\title{
Army Cardiac Unit - Cardiac Catheter Patients, 1991 - A Review
}

\author{
Capt A E Kiltie
}

MA, MRCP(UK) RAMC

\author{
Lt Col $N$ Ineson \\ MRCP(UK), RAMC
}

\section{Army Cardiac Unit, Queen Elizabeth Military Hospital, Woolwich, London SE18 4QH}

SUMMARY: Ninety three cardiac catheterisations were carried out at St Thomas' Hospital on behalf of the Queen $\stackrel{\unrhd}{\unrhd}$ for further intervention. Sixteen $(20 \%)$ of the 79 patients, thought to have ischaemic heart disease, had normal $\vec{\circ}$ coronary arteries, but on further analysis of this group none could reasonably have been excluded from further $\overrightarrow{.}$ investigation with angiography. Fewer military patients than civilians were recommended for active intervention. $\vec{\omega}$ This probably reflects the fact that most of the military patients were under 50 years old, had had a myocardial infarction or angina and therefore warranted catheterisation because of their young age.

\section{Introduction}

The Army Cardiac Unit based at the Queen Elizabeth Military Hospital, Woolwich (QEMH), is responsible for the diagnosis, management and rehabilitation of the majority of Army personnel with cardiac disease. It acts as an interface with major UK teaching hospitals for invasive cardiological investigations and subsequent treatments. As these are expensive, it is important to audit our referrals for such procedures.

\section{Patients and Methods}

All patients (90) seen by the Army Cardiac Unit were studied by retrospective analysis of their QEMH case notes. These patients were referred by this unit for cardiac investigation to St Thomas' Hospital, London. A small number of patients (five in 1991) were referred directly by other units to other specialist hospitals, either at home or overseas (not studied here). The subjects comprised military personnel, dependants, UKBC overseas, retired servicemen, civilians local to military hospitals in UK and two Falkland Islanders.

Fourteen patients $(16 \%)$ were referred for investigation of congenital and acquired non-ischaemic heart disease. The remaining 76 were referred for investigation of known or possible ischaemic heart disease. The notes of one patient were not available. Of the other 75 , all except 12 had thallium scanning (as part of the routine Army Cardiac Unit work-up) before catheterisation.

Patients were categorised into those with either significant single, double or triple vessel disease or those who had previously undergone angioplasty or coronary artery bypass grafting, or those whose coronary arteries were normal on angiography ("normals"). A coronary artery was not considered significantly stenosed if the maximum stenosis in that vessel was reported as less than $50 \%$ of the vessel diameter.

\section{Risk Factors}

Risk factors were studied in all ischaemic heart disease ${ }_{\mathrm{N}}$ patients where the data was available.

Family history was considered positive if at least one first degree relative was known to have develope्d ischaemic heart disease under the age of 60 .

Hypertension - the patient was considered hypertensive if there was a history of hypertension, or if the blogi $\overrightarrow{ }$ pressure was noted to be at least $95 \mathrm{mHg}$ diastolic of admission, and a total of at least three measuremen during that admission were at least at this level.

Diabetes - the patient was considered to be diabetic there was a history of diabetes or if the blood glucose of thallium admission was elevated (fasting blood glucose $>$ $6.7 \mathrm{mmol} / \mathrm{L}$ ).

Cholesterol - the highest value in the case notes was $\overrightarrow{\overrightarrow{0}}$ recorded for the purposes of this study. In the 6 patients 3 on lipid-lowering drugs, the levels recorded were taken pre-treatment. Most of the levels were fasting, but some results were from other hospitals and therefore the fasting 3 state of these could not be guaranteed where this was not specifically recorded. Similarly HDL levels were not always available, either because the result came from $\vec{\Phi}$ another hospital or because at cholesterol levels $<5.4 \mathrm{mmol} / \mathrm{L} \mathrm{HDL}$ estimations are not made in the QEMH laboratory.

Alcohol - patients were directly questioned about $\delta$ alcohol consumption at the time of their thallium scan admission. No patient admitted to a consumption of 0 greater than 21 units per week, therefore alcohol was not $\rightarrow$ looked at further in the study.

Smoking-patients were categorised into those who had either never smoked or had not smoked for at least 10 \% years, and those who were still smoking or had smoked 0 within the last 10 years.

Body Mass Index - was calculated as weight㝏 (kg)/height(m)2. 


\section{Statistics}

Means and standard deviations were calculated. Means were compared by Student's T-test.

Thallium scintigraphy involved exercising the patient to target heart rate or limiting symptoms and injecting $70 \mathrm{MBq}$ of thallium 201 as thallium chloride intravenously one minute before stopping the test. The patient was imaged immediately using a Picker/Nuclear Diagnostic gamma camera with a high sensitivity collimator. Images were computer acquired on a $64 \times 64$ matrix for 300,000 counts with the patient in the anterior, left anterior oblique (LAO) $45^{\circ}$ and LAO $70^{\circ}$ positions. After a 3-4 hour delay, scanning was repeated to obtain the rest images. Paired images were blown up, interpolated and background subtracted before being displayed side by side.

In those patients who had undergone thallium scanning, the sensitivities and specificities of maximal exercise testing and thallium scanning were calculated.

For maximal exercise testing the following sensitivities and specificities were calculated - ST changes alone, ST changes and symptoms, ST changes or symptoms, in all cases including and excluding borderline changes. Significant ST depression was defined as at least $2 \mathrm{~mm}$ planar or down sloping ST segments, at $80 \mathrm{msec}$ from the $\mathrm{J}$ point. Borderline changes were said to occur where depression was down sloping or planar and at least $1 \mathrm{~mm}$ in size, $80 \mathrm{msec}$ after the $J$ point. Symptoms were considered significant if they were thought to be cardiac in origin. Borderline symptoms included eg. fatigue and breathlessness where it was possible that these were due to cardiac causes. All METs were reviewed (by the first author) as original reporting had been performed by at least 5 different doctors.

The sensitivities and specificities of the thallium scans were also determined, a) where all scan defects were included, b) where only those showing reversible defects (1) were included (i.e. those with fixed defects only were excluded), and c) where those scans with abnormalities in only one view were considered normal, and those scans showing reversible defects in one view only with fixed defects in one or more views were not included (cf. b)). In four cases it was not possible to assess whether an abnormality was present in only one view from the wording of the report. No formal attempt at follow up was made due to the short time span from the catheterisation to study and because many were referred back to the care of other service physicians or hospitals both in UK or abroad.

\section{Results}

Ninety patients underwent cardiac catheterisations at St Thomas' Hospital from QEMH in 1991. A total of 93 procedures were carried out, three patients having undergone cardiac catheterisation twice.

One patient who had double vessel disease and who was subsequently recommended for medical management, did not have his notes available at the time of the study.
Fourteen patients had cardiac catheters for nonischaemic heart disease.

Twelve patients had cardiac catheters for known or $\mathbb{Q}$ suspected ischaemic heart disease, who did not have? relevant preceding thallium scans.

The remainder previously underwent thallium scanning. Thirteen had significant single vessel disease, 7 significant $\overrightarrow{\overrightarrow{\vec{F}}}$ double vessel disease and 17 significant triple vessel disease (including right coronary artery with left main $\frac{\square}{0}$ stem disease). Seven patients underwent cardiac $\overline{\bar{c}}$ catheterisation post-angioplasty. One patient had two $\widetilde{\nabla}$ post-angioplasty catheterisation in 1991, and another (with single vessel disease), had both a pre-angioplasty and a post-angioplasty catheterisations in 1991. Four patients had had previous coronary artery bypass graft surgery; one of these patients had two post-bypass $\stackrel{\omega}{\sigma}$ catheterisations in 1991. Sixteen patients had normal coronary arteries at angiography.

The mean time from thallium scan to cardiac? catheterisation was 73.9 days (SD 95.0, range 1-462 $\overrightarrow{\text { D. }}$ days). One post-bypass graft patient had his catheterisation 15 days before his thallium scan which was used to determine the need for subsequent 0 angioplasty, but there was no intervening intervention oㅗ응 myocardial infarction from time of catheter to thalliu角 scan. Some of the patients who did not have their catheter

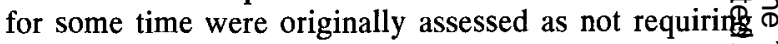
further intervention, but later developed further chest pa通 $\overrightarrow{0}$ after thallium scanning. However, none of the patiends had a myocardial infarct or angioplasty in the interim.

Table 1

Risk factors for ischaemic heart disease

\begin{tabular}{|c|c|c|c|}
\hline & "Normal" & all IHD patients & SVD only \\
\hline $\mathrm{n}=$ & 16 & 59 & 15 \\
\hline $\mathrm{M}: \mathrm{F}$ & $13: 3$ & $53: 6$ & $13: 2$ \\
\hline mean age & 43.0 & 50.6 & 44.8 \\
\hline$(\mathrm{SD})$ & (8.59) & (11.17) & $(9.40)$ \\
\hline family history & $\begin{array}{l}26.7 \% \\
(n=15)\end{array}$ & $\begin{array}{l}38.8 \% \\
(\mathrm{n}=54)\end{array}$ & $\begin{array}{l}69.2 \% \\
(n=13)\end{array}$ \\
\hline hypertension & $18.8 \%$ & $23.7 \%$ & $33.3 \%$ \\
\hline diabetes & 0 & $\begin{array}{l}5.17 \% \\
(n=58)\end{array}$ & 0 \\
\hline $\begin{array}{l}\text { mean cholesterol } \\
\text { (SD) }\end{array}$ & ol $\begin{array}{c}5.82 \\
(1.38)\end{array}$ & $\begin{array}{c}7.02 \\
(1.21) \\
(n=54)\end{array}$ & $\begin{array}{c}6.81 \\
(0.99) \\
(n=14)\end{array}$ \\
\hline $\begin{array}{l}\text { mean HDL } \\
\text { (SD) }\end{array}$ & $\begin{array}{c}2.49 \\
(0.52) \\
(\mathrm{n}=5)\end{array}$ & $\begin{array}{l}1.96 \\
(0.50) \\
(n=41)\end{array}$ & $\begin{array}{l}1.93 \\
(0.50) \\
(n=10)\end{array}$ \\
\hline $\begin{array}{r}\text { smoking a) } \\
\text { b) }\end{array}$ & $\begin{array}{l}8 \\
8\end{array}$ & $\begin{array}{c}21 \\
37 \\
(\mathrm{n}=58)\end{array}$ & $\begin{array}{c}2 \\
13\end{array}$ \\
\hline $\begin{array}{l}\text { mean BMI } \\
\text { (SD) } \\
\text { alcohol }\end{array}$ & $\begin{array}{c}26.0 \\
(4.10) \\
n=21 \mathrm{U} / \mathrm{wk}\end{array}$ & $\begin{array}{c}26.1 \\
(2.95) \\
\text { none }>=21 \mathrm{U} / \mathrm{wk}\end{array}$ & $\begin{array}{c}26.9 \\
(3.27) \\
n e>=21 \mathrm{U} / \mathrm{w}\end{array}$ \\
\hline
\end{tabular}

Smoking: a) = patients who had never smoked or who stopped at least ten years before the onset of symptoms

b) = patients who smoked until the onset of symptoms or shortly 
beforehand or who were still smoking at the time of their admission for thallium scan, or catheterisation, in the case of those who did not undergo thallium scanning.

\section{Risk factors}

See Table 1

A comparison was made of means and percentages between the "normal" patients and those with ischaemic heart disease. The "normals" were compared with those patients with single vessel disease, as there was no significant difference in age or sex ratio, and also with the entire group of ischaemic heart disease patients. When all the "normals" were compared with all the ischaemic heart disease patients, the following were significantly different - age $(p<0.02)$, cholesterol $(p<0.002)$ and HDL cholesterol $(p<0.05)$. When the "normals" were compared with the single vessel disease patients, only cholesterol was significantly different $(p<0.05)$. patients were recommended for surgery as a result of their 1991 catheter.

\section{Military patients}

Thirty-six patients were investigated for known or $\bigcirc$ possible ischaemic heart disease (with 38 catheterisations being carried out), 7 were investigated for non-ischaemic? heart disease.

The risk factors in military patients are shown in Table $\frac{\text { ? }}{\circ}$ 4 , and their outcomes in terms of intervention in Table 5. $\frac{\mathrm{C}}{5}$ Of those military patients who had not had previous $\overline{\bar{c}}$ bypass surgery or angioplasty, 5 had had a myocardial $\vec{\mathbb{}}$ infarction and no further symptoms, $10 \mathrm{had}$ angina but no history of infarction, 8 had had a myocardial infarction क and angina, and 3 had atypical chest pain.

\section{Normals}

Some of the features of the group with normal coronaryo arteries are summarised in Table 6.

Table 2

Sensitivities and specificities of maximal exercise tests and thallium scans

\section{Maximal exercise tests -}

a) ECG changes alone, including borderline changes

b) ECG changes and symptoms, including borderline changes

c) ECG changes or symptoms, including borderline changes

d) ECG changes alone, borderline considered normal

e) ECG changes and symptoms, borderline considered normal

f) ECG changes or symptoms, borderline considered normal

sensitivity
$60.9 \%$
$45.7 \%$
$76.1 \%$
$43.5 \%$
$34.8 \%$
$56.7 \%$

In one case of single vessel disease the patient had left bundle branch block throughout; in one case of triple vessel diseags (thallium performed in Germany) the symptoms were not recorded.

\section{Thallium scans -}

a) all scans included

b) reversible scan defects only

c) scans abnormal in one view only considered normal; scans with ischaemia in 1 view only but infarction in one or more views

$$
\begin{gathered}
\text { sensitivity } \\
100 \% \\
100 \% \\
92.1 \%
\end{gathered}
$$

specificity

$77.8 \%$

$38.9 \%$

$66.7 \%$

$88.9 \%$

$55.6 \%$ not included

\section{Sensitivities and specifications}

See Table 2.

In two post-angioplasty patients all residual lesions were less than $50 \%$ stenosed and so they were considered "normal" for the purpose of analysing sensitivities and specificities.

\section{Outcome}

Treatment outcomes are shown in Table 3. Patients were classified into those recommended for surgery, those recommended for angioplasty, and those advised to continue with medical treatment. Some of the angioplasties (performed as a result of the patient's 1991 cardiac catheter) failed, resulting in a requirement for surgery or laser angioplasty; but this has not been taken into account in this table. However some post-angioplasty

\section{Discussion}

Cardiac catheterisation is used to select those patients $\frac{2}{\sigma}$ requiring further intervention. It is not to be contemplated lightly as it has it own morbidity and mortality $(<0.05 \% ?$ (3)). Therefore in a series of patients one is aiming for a high proportion of them to require further intervention.

In this series, 13 of $14(93 \%)$ patients investigated with an initial diagnosis of non-ischaemic heart disease were recommended for surgery as a result of their cardiac 5 catheterisation. The remaining patient had a secundum $\frac{D}{6}$ ASD with pulmonary hypertension and was to be anticoagulated for 6 months then reassessed. Of the 12 sets of $\sigma$ coronary arteries reported upon, all were normal.

In the ischaemic heart disease group, $58.2 \%$ were recommended for further intervention, i.e. angioplasty or ${ }^{\omega}$ coronary artery bypass grafting, including 3 who were? 
provisionally recommended for angioplasty if other features such as on-going ischaemia or symptoms were supportive of this course of action.

A total of $59(63.4 \%)$ of the 93 catheterisations were recommended for further intervention, which is a favourable percentage.

Table 3

Patient treatment outcomes

\begin{tabular}{lcccc}
\hline & Medical & Angioplasty & Surgery & Total \\
Single vessel & 5 & 9 & 1 & 15 \\
Double vessel & 4 & 1 & 3 & 8 \\
Triple vessel & - & 1 & 20 & 21 \\
Post-angioplasty & 5 & 3 & 2 & 10 \\
Post-CABG & 3 & 6 & - & 9 \\
Normal & 16 & - & - & 16 \\
\hline Subtotal & 33 & $20^{*}$ & 26 & 79 \\
Non-IHD & 1 & - & 13 & 14 \\
\hline Total & 34 & 20 & 39 & 93 \\
\hline \hline
\end{tabular}

*including 3 patients for consideration of angioplasty after other factors considered, eg. further symptoms. scintigraphy (or dobutamine scanning where maximak exercise testing inappropriate, e.g. in patients with lower limb arthritis or intermittent claudication) are performed $\stackrel{\mathbb{Q}}{\varrho}$ The aim of the protocol is to select those for cardiao? catheterisation, thereby minimising the number of unnecessary catheterisations, and minimising the number? of patients where catheterisation might have been of value but which was not carried out.

In 1991 the total number of thallium scans performed was 285 (including post-angioplasty check scans). Sixtye five patients, who had preceding thallium scans (although some were performed before 1991) underwent cardiac catheterisation. Therefore, approximately $22 \%$ of patientsos having thallium scans have subsequent cardiac catheters. $\overrightarrow{0}$

It is known that a normal thallium scan gives the patientan excellent prognosis in the following two years and $x \bar{\omega}$ normal thallium scan is the most useful predictor of normal coronary arteries in patients with chest pain (3) This study did not look at those undergoing thallium? scanning who did not subsequently undergo cardiact catheterisation, but in general, those who were not selected either had normal scans, scans showing not significant ischaemia, or scans showing no significanto deterioration from previous scans.

It could be argued that in terms of cost-cutting, it might be cheaper to select patients on the basis of maxingak

Table 4

Risk factors in military patients

\begin{tabular}{|c|c|c|c|c|c|c|c|}
\hline & $\begin{array}{l}\text { SVD } \\
(n=9)\end{array}$ & $\begin{array}{l}2 V D \\
(n=2)\end{array}$ & $\begin{array}{l}3 V D \\
(n=6)\end{array}$ & $\begin{array}{c}\text { angio* } \\
(\mathbf{n}=8)\end{array}$ & $\begin{array}{c}\text { CABG } \\
(\mathbf{n}=2)\end{array}$ & $\begin{array}{c}\text { normal } \\
(n=9)\end{array}$ & $\begin{array}{c}\text { total } \\
(n=36)\end{array}$ \\
\hline male:female & $9: 0$ & $2: 0$ & $6: 0$ & $8: 0$ & $2: 0$ & 9:0 & $36: 0$ \\
\hline \multirow[t]{2}{*}{ age mean (SD) } & 41.1 & 40.5 & 43.3 & 43.6 & 44.5 & 41.9 & 42.4 \\
\hline & $(7.10)$ & (3.54) & $(3.78)$ & $(10.86)$ & $(6.36)$ & (9.39) & $(7.76)$ \\
\hline family history & $\begin{array}{l}62.5 \% \\
(\mathrm{n}=8)\end{array}$ & $100 \%$ & $33.3 \%$ & $25 \%$ & $50 \%$ & $11.1 \%$ & $\begin{array}{l}37.1 \% \\
(\mathrm{n}=35)\end{array}$ \\
\hline hypertension & $22.2 \%$ & 0 & 0 & $25 \%$ & $50 \%$ & $33.3 \%$ & $22.2 \%$ \\
\hline diabetes & 0 & 0 & 0 & 0 & 0 & 0 & 0 \\
\hline cholesterol & 6.94 & 6.38 & 7.47 & 6.87 & 9.22 & 6.14 & 6.91 \\
\hline mean (SD) & $(1.08)$ & $(1.82)$ & $(0.87)$ & $(1.35)$ & $(2.28)$ & $(1.64)$ & (1.46) \\
\hline \multirow[t]{3}{*}{ HDL mean (SD) } & 2.00 & 2.30 & 1.80 & 1.70 & 1.50 & 2.12 & 1.87 \\
\hline & $(0.39)$ & & $(0.47)$ & $(0.62)$ & $(0.42)$ & $(0.11)$ & $(0.45)$ \\
\hline & $(n=6)$ & $(\mathrm{n}=1)$ & $(n=5)$ & $(n=4)$ & $(n=2)$ & $(\mathrm{n}=2)$ & $(n=20)$ \\
\hline smoking** & $0 ; 9$ & $0 ; 2$ & $2 ; 4$ & $3 ; 5$ & $1 ; 1$ & $5 ; 4$ & $11 ; 25$ \\
\hline \multirow[t]{2}{*}{ BMI mean (SD) } & 27.0 & 29.2 & 24.2 & 25.3 & 26.2 & 25.5 & 25.9 \\
\hline & $(4.20)$ & $(2.05)$ & $(2.76)$ & $(1.71)$ & (3.11) & $(3.14)$ & (3.16) \\
\hline
\end{tabular}

*these patients are post-angioplasty and include 2 patients who did not undergo thallium scanning.

**as in Table 1.

At QEMH the protocol for investigation of ischaemic heart disease involved admission of the patient for three days, when a history, including a detailed history of risk factors, physical examination, ECG, chest radiograph, echocardiography, blood tests including fasting glucose and lipids, and maximal exercise testing with thallium exercise testing alone rather than combined with thallium scintigraphy. However, Table 2 shows the sensitivities $N$ and specificities of the various tests. Thallium scintigraphy was extremely sensitive but relatively non specific. However, if those with only one abnormal view (of 3 views) were considered normal and those showing 
Table 5

Outcome recommendations for military personnel

SVD 2VD 3VD normal angio- CABG total $(n=9) \quad(n=2) \quad(n=6) \quad(n=9)$ plasty $(n=2)$ $(n=10)$

$\begin{array}{lllllllr}\text { Medical } & 4 & 1 & - & 9 & 5 & - & 19 \\ \text { Angioplasty } & 4 & - & 1 & - & 3 & 2 & 10 \\ \text { Surgery } & 1 & 1 & 5 & - & 2 & - & 9\end{array}$

testing alone in terms of sensitivity and specificity in this group of patients. Kotler and Diamond (1) did not consider thallium scanning clearly preferable to exercise testing (except in a few clearly defined circumstances), $\mathrm{O}$ but, as the procedure is well established at QEMH, and as all resources are "in-house", with the only additional expense being the radioisotope, in real terms the cost tos? the army is probably minimal.

Kotler and Diamond (1) in a large clinical review, gave흐 an overall sensitivity of $68-96 \%$ (mean $84 \%$ ), and overall $\frac{\bar{\sigma}}{\sigma}$ specificity of $65-100 \%$ (mean $87 \%$ ). Therefore in our $\stackrel{\Phi}{\circ}$

Table 6

Features of patients with normal coronary arteries

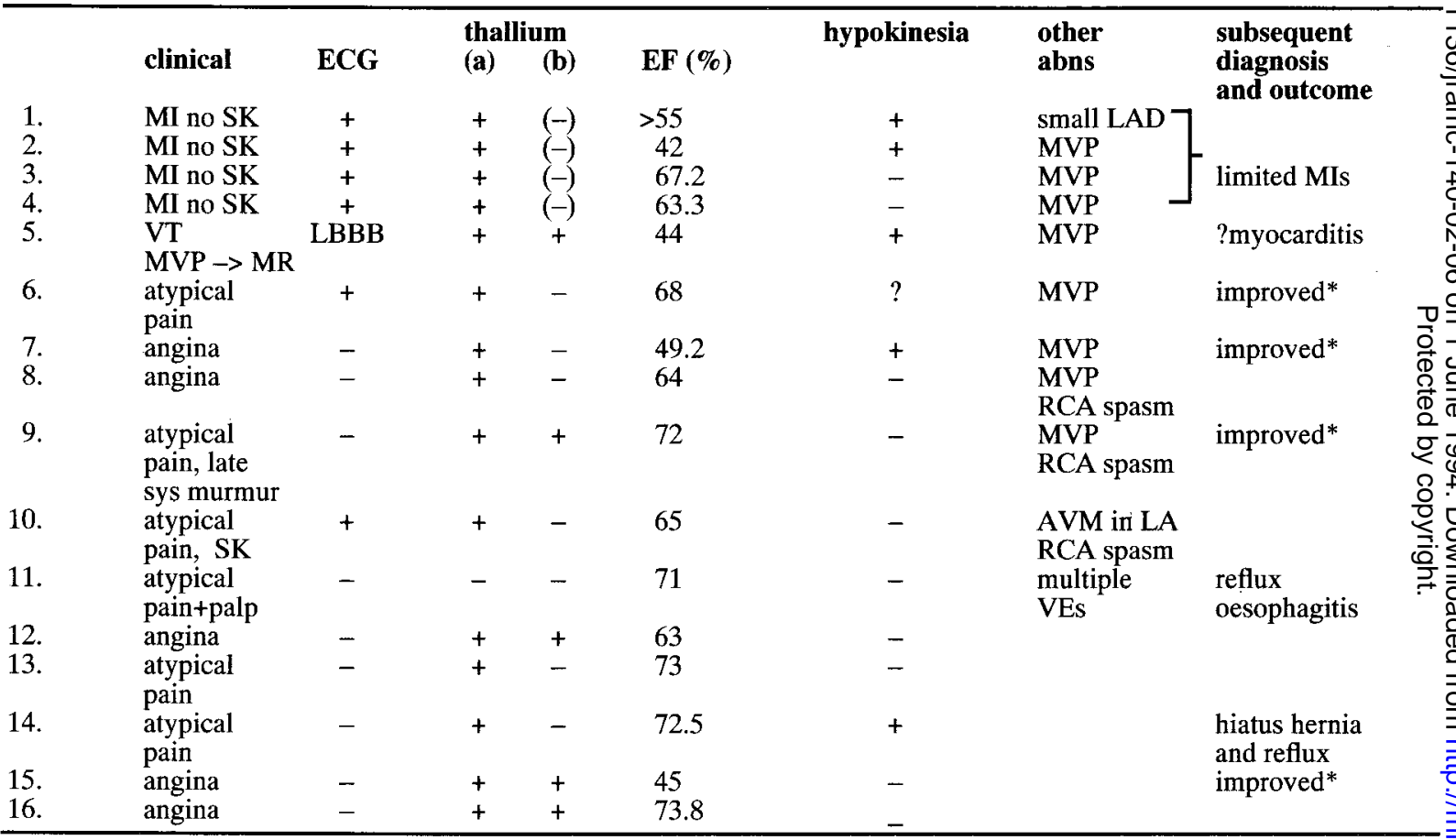

$(E C G=12$ lead resting $E C G, M I=$ myocardial infarction, $S K=$ streptokinase, thallium $(a)=$ as per 2 . a) in table 2 , thallium $(b)=$ as per 2 . c) in table 2, EF = ejection fraction, hypokinesia = hypokinesia detected at catheterisation, other abns = other abnormalities detected on cardiac catheter, $\mathrm{MVP}=$ mitral valve prolapse, $\mathrm{MR}=$ mitral regurgitation, $\mathrm{AVM}=$ arteriovenous malformation, $\mathrm{LA}=$ left atrium)

*improved spontaneously with reassurance

infarction only were not included in the analysis, specificity was improved from $5.6 \%$ to $50 \%$ with only a $7.9 \%$ reduction in sensitivity to $92.1 \%$. The most sensitive exercise tests were those where ECG changes or symptoms including borderline cases were considered positive ( $76.1 \%$ sensitivity, but only $38.9 \%$ specificity), while the most specific were those where both ECG changes and symptoms were completely positive $(88.9 \%$ specific, but only $34.8 \%$ sensitive). Therefore, thallium scanning would appear to be superior to maximal exercise study specificity was not as good but sensivity was at the upper end of the range of values. This may reflect the $\mathrm{o}$ population studied. Thallium scanning is best for those patients with an intermediate probability of having을. ischaemic heart disease at the time of testing as well as defining the prognosis of patients with known oro suspected coronary artery disease, especially in those with $\sim$ a previous MI (1). A man in his 40 's with typical angina స్心 or atypical chest pain has a $40-50 \%$ chance of having IHDO (4). Therefore the result of the thallium scan can alter the 
probability significantly. A large proportion of our study population had an intermediate probability of ischaemic heart disease, having chest pain and being in their 40 's, or had had a previous MI and required a prognosis.

No active intervention was recommended in any of the patients with "normal" coronary arteries. In an audit of cardiac catheterisations, bearing in mind the expense, morbidity and mortality of the procedure, it would seem appropriate to examine this group to assess whether any of these catheterisations might have been omitted.

Fifteen of the 16 "normals" had abnormal thallium scans (3 of these had only irreversible defects). The patient with a normal scan was a 35 year old female military dependent with atypical chest pain and palpitations and a strong family history of ischaemic heart disease. If the thallium scans in which only one of three views was positive were considered normal then only 9 had abnormal scans, including four with irreversible defects only.

Berger, Abramowitz et al (3) studied 41 patients with chest pain and normal coronary arteries and found $\mathbf{1 1}$ with abnormal thallium scans. No clinical factor was significantly associated with these false positive scans, but 9 of the 11 patients had at least one cardiac abnormality, including 3 with mitral valve prolapse. In our study, 8 patients had mitral valve prolapse detected on catheterisation, and this is known to produce abnormal thallium scans. Three cases were known about prior to investigation, 2 of which were detected on echocardiogram.

Butman, Chandraratna et al (5) found that thallium scanning was not entirely. successful in differentiating patients with mitral valve prolapse and coronary artery disease from those without coronary artery disease, in a study of 24 patients with mitral valve prolapse, 10 of whom had coronary artery disease. There were a total of 15 abnormal thallium scans in the study, 6 of which were in the coronary artery disease patients.

Possible mechanisms to explain thallium scan defects in patients with normal coronary arteries and mitral valve prolapse include - localised cardiomyopathy resulting in ischaemia and fibrosis, coronary spasm causing infarction, and coronary embolism with subsequent resolution of the clot (from clots on the myxomatous mitral valve) (5). In those patients without mitral valve prolapse, small vessel disease might also explain thallium abnormalities in the presence of normal coronary arteries.

In our study only 3 of the cardiac catheter studies were entirely normal and all of these had abnormal thalliums, 2 giving histories suggestive of angina, the other being a 45 year old soldier with a positive family history, "stress"related hypertension and a cholesterol of $8.5 \mathrm{mmol} / \mathrm{L}$.

It is also of note that when the "normals" are compared with all of the ischaemic heart disease patients, only mean cholesterol, mean HDL and mean age are significantly different in terms of risk factors. When the "normals" are compared with those with single vessel disease, with no significant difference in mean age or sex ratio between the groups, then only mean cholesterol was significantly different.

Seven (44\%) of the normal group had abnormal resting ECGs. Thirty-two (65.3\%) of those with ischaemic heart disease (excluding those not undergoing thallium scanning) had abnormal resting ECGs.

From the above information, then, it would be difficult to choose any of the "normal" patients in whom it would have been reasonable to have omitted catheterisation.

Some authorities would make a case for all young patients who have sustained a myocardial infarction (regardless of symptoms), or those suffering from angina at a young age (ie. $<50$ years old) having a cardiac catheterisation, regardless of the need for intervention subsequently. In this study, 21 patients under 50 years old had sustained a myocardial infarction. (ie. $28.4 \%$ of the patients studied). A further 11 had angina, (ie. $14.9 \%$ of study population). Of the 36 military patients in the study, $16(44.4 \%)$ were under 50 and had a history of myocardial infarction, and a further 10 patients $(27.8 \%)$ under 50 years old had angina, giving a total of 26 (72.2\%) military patients. This would account for the lower percentage of military patients undergoing active intervention post-catheterisaton compared with the overall study population ( $50 \%$ of $58.2 \%$ ).

In terms of risk factors, it is perhaps not surprising that a large percentage of the ischaemic heart disease patients had a positive family history, a high proportion had elevated cholestral levels, and a high proportion smoked Although only $5.3 \%$ had diabetes, this probably reflects the population studied with none of the serving soldiers? being diabetic. What is less expected is that the mean body mass index was only just above that recommended ie. 25.9 of 25.0 . It is also of interest that the "normals" only differed from the ischaemic heart disease group in having a lower mean cholesterol (and higher HDL level when compared with all ischaemic heart disease patients) with the rest of the risk factor profile being not significantly different.

\section{Acknowledgements}

We are grateful to Dr M Webb-Peploe, Consultant Advisor to the Army in Cardiology, St Thomas' Hospital, London, and to Mr B Williams, Consultant Advisor in Cardiothoracic Surgery to the Army, for their contributions to the management of these patients.

We are grateful to SSgt M Coleman for supplying the necessary technical information on thallium scintigraphy.

\section{REFERENCES}

1. Kotler T S, Diamond G A. Exercise Thallium Scintigraphy in the Diagnosis and Prognosis of Coronary Artery Disease. Ann Intern Med 1990; 113: 684-702. 
2. Weatherall D J, Ledingham J G G, et al. Oxford Textbook of Medicine, 2nd Edition. Oxford Medical Publications, 1987:13.50.

3. Berger B C, Abramowitz R, Chan H, et al. Abnormal Thallium-201 Scans in Patients with Chest, Pain and Angiographically Normal Coronary Arteries. Am J Cardiol 1983; 52: 365-370.
4. Fogelman I, Maisey M. An Atlas of Clinical Nuclear Medicine, Martin Dunitz, 1988: 767.

5. Butman S, Chandraratna Pan, Milne N, et al. Stress Myocardial Imaging in Patients with Mitral Valve Prolapse: Evidence of a Perfusion Abnormality. Cathet Cardiovasc Diagn 1982; 8: 243-252.

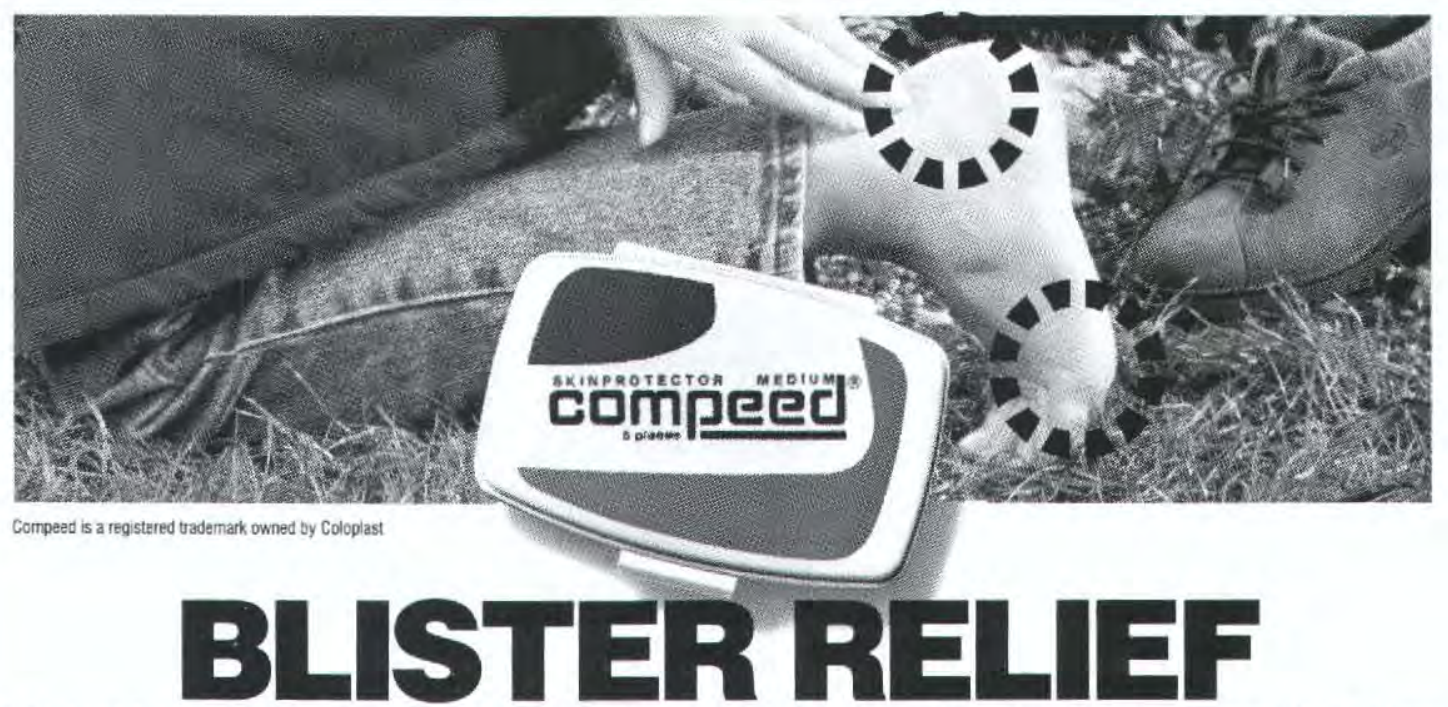

- Compeed acts like an extra layer of protective skin and prevents further damage
- Compeed gives instant pain relief and creates perfect healing conditions
- Available from larger Boots stores, chemists, sports and outdoor pursuit shops

Distributed in the UK by 